\title{
Article \\ Sulfur-Doped Graphdiyne as a High-Capacity Anode Material for Lithium-Ion Batteries
}

\author{
Fanan Kong, Yong Yue, Qingyin Li and Shijie Ren*(D)
}

check for updates

Citation: Kong, F.; Yue, Y.; Li, Q.;

Ren, S. Sulfur-Doped Graphdiyne as a High-Capacity Anode Material for Lithium-Ion Batteries. Nanomaterials 2021, 11, 1161. https://doi.org/ 10.3390/nano11051161

Academic Editor:

Francisco Ruiz-Zepeda

Received: 24 March 2021

Accepted: 26 April 2021

Published: 29 April 2021

Publisher's Note: MDPI stays neutral with regard to jurisdictional claims in published maps and institutional affiliations.

Copyright: (c) 2021 by the authors. Licensee MDPI, Basel, Switzerland. This article is an open access article distributed under the terms and conditions of the Creative Commons Attribution (CC BY) license (https:// creativecommons.org/licenses/by/ $4.0 /)$.
State Key Laboratory of Polymer Materials Engineering, College of Polymer Science and Engineering, Sichuan University, Chengdu 610065, China; xlfc12138@stu.scu.edu.cn (F.K.); 2018223090115@stu.scu.edu.cn (Y.Y.); qingyinli@scu.edu.cn (Q.L.)

* Correspondence: rensj@scu.edu.cn

\begin{abstract}
Heteroatom doping is regarded as a promising approach to enhance the electrochemical performance of carbon materials, while the poor controllability of heteroatoms remains the main challenge. In this context, sulfur-doped graphdiyne (S-GDY) was successfully synthesized on the surface of copper foil using a sulfur-containing multi-acetylene monomer to form a uniform film. The S-GDY film possesses a porous structure and abundant sulfur atoms decorated homogeneously in the carbon skeleton, which facilitate the fast diffusion and storage of lithium ions. The lithium-ion batteries (LIBs) fabricated with S-GDY as anode exhibit excellent performance, including the high specific capacity of $920 \mathrm{~mA} \mathrm{~h} \mathrm{~g}^{-1}$ and superior rate performances. The LIBs also show long-term cycling stability under the high current density. This result could potentially provide a modular design principle for the construction of high-performance anode materials for lithium-ion batteries.
\end{abstract}

Keywords: sulfur-doped graphdiyne; bottom-up synthesis; anode material; lithium-ion batteries

\section{Introduction}

As one of the most promising energy storage devices, rechargeable lithium-ion batteries (LIBs) have drawn much attention because of their large energy density, high working voltage, and long cycling life [1,2]. Electrode materials are the core components of LIBs and largely determine their ultimate performance, and the research on anode materials has received extensive attention [3-5]. Carbon materials, including graphite and relatively newly developed carbon nanotubes and graphene, are the most used anode materials for LIBs [6-9]. However, their application in LIBs is restricted by limited lithium storage capacity, low-rate capability, poor capacity retention, etc. [10]. Thus, it is still of great interest to develop novel carbon materials for LIBs application.

Recently, a newly artificial carbon allotrope, graphdiyne (GDY), which is constructed by $\mathrm{sp}^{2}$ and $\mathrm{sp}$ carbon atoms, has been developed [11]. Due to its two-dimensional allcarbon structure and intrinsic nanoporosity, GDY and its derivatives exhibit promising electronic, optical, and mechanical properties and thus have been extensively studied as active materials in many different applications [12-14]. In the energy storage area, GDY-based materials exhibit a great potential to be used as anode materials for LIBs with large capacity, high output power, and excellent stability [15]. To improve the electrochemical performance of GDY further, heteroatoms such as nitrogen (N) [16,17], sulfur (S) [18], chlorine (Cl) [19], hydrogen (H) [20], boron (B) [21] and fluorine (F) [22] have been doped into GDY to improve its conductivity and wettability. Thermal annealing of GDYs at high temperatures with the presence of heteroatom-containing small molecules is a convenient top-down method for the preparation of heteroatom-doped GDYs (HD-GDYs). However, this method suffers from some drawbacks, including uncertainty of doping sites and uncontrollability of doping amounts. Another method to prepare HD-GDYs is the direct polymerization of heteroatom-containing multi-acetylene monomers. This bottom-up method could essentially control the content and location of the heteroatoms. Among these 
HD-GDYs, nitrogen-doped GDYs have been extensively studied and used as highly promising candidates for the fabrication of advanced energy storage devices [17,23,24].

Compared with nitrogen, sulfur has a larger atom size and a lower electronegativity. Doping sulfur into two-dimensional carbon materials could expand the interlayer distance, create active sites, and significantly boost the electronic properties of carbonaceous materials $[25,26]$. Recently, some studies have revealed that sulfur-doped GDYs (S-GDYs) prepared by the top-down method displayed improved electrochemical properties in LIBs, including high-rate performance and excellent stability [27,28]. Meanwhile, bottom-up synthesis of sulfur-containing conjugated polymers, especially those based on polythiophene, has been studied for energy storage applications due to their high intrinsic conductivity and abundant electroactive sites [29]. For instance, Zhang et al. reported the structural design of thiophene-containing conjugated microporous polymers as high-performance anode materials for LIBs [30]. Recently, Wang et al. prepared thiophdiyne films as artificial protective layers for aluminum foil in dual-ion batteries, resulting in improved cycling stability [31]. However, there has been no report on the application of thiophene-based S-GDYs as the anode materials for LIBs. In this work, we designed and prepared sulfurdoped graphdiyne (S-GDY) with extended $\pi$-conjugated carbon skeletons comprised of butadiyne linkages and thiophene rings through a bottom-up synthetic strategy. The obtained S-GDY exhibits enhanced electrochemical performance due to the synergistic effect of sulfur doping and porous structure.

\section{Materials and Methods}

\subsection{Materials}

Trimethylsilyl acetylene, 2,3,4,5-tetrabromothiophene, potassium fluoride, 1,3,5-tribro mobenzene, bis(triphenylphosphine)palladium (II) dichloride, copper (I) iodide, trimethylamine, pyridine, and tetrahydrofuran were all purchased from Adamas. Tetrahydrofuran was dried by distillation and other chemicals were used as received without any further purification.

\subsection{Experimental Section}

The monomer 2,3,4,5-tetraethynylthiophene (M1) was obtained following the synthetic route shown in Figure S1.

\subsubsection{Synthesis of 2,3,4,5-tetrakis[(trimethylsilyl)ethynyl]-thiophene (2)}

Under Ar atmosphere, trimethylsilyl acetylene (1.47 g, $15 \mathrm{mmol})$, 2,3,4,5-tetrabromothio phene ( $1 \mathrm{~g}, 2.5 \mathrm{mmol}$ ), bis(triphenylphosphine)palladium (II) dichloride ( $53 \mathrm{mg}, 0.075 \mathrm{mmol}$ ), and copper (I) iodide $(14 \mathrm{mg}, 0.075 \mathrm{mmol})$ were dissolved in the triethylamine $(60 \mathrm{~mL})$. The reaction mixture was heated to $80^{\circ} \mathrm{C}$ and stirred for $24 \mathrm{~h}$. Then, water $(200 \mathrm{~mL})$ was added and the water phase was extracted with dichloromethane and dried over $\mathrm{Na}_{2} \mathrm{SO}_{4}$. The solvent was evaporated and the residue was chromatographed on silica gel with n-hexane to give 2,3,4,5-tetrakis[(trimethylsilyl)ethynyl]-thiophene as white solid (480 $\mathrm{mg}$, 41\%). ${ }^{1} \mathrm{H}$ NMR $\left(400 \mathrm{MHz}, \mathrm{CDCl}_{3}\right): \delta(\mathrm{ppm}) 0.27 .{ }^{13} \mathrm{C} \mathrm{NMR}\left(101 \mathrm{MHz}, \mathrm{CDCl}_{3}\right): \delta(\mathrm{ppm})$ 121.17, 119.49, 105.62, 95.02, - 0.36. Anal. Calcd for $\mathrm{C}_{24} \mathrm{H}_{36} \mathrm{SSi}_{4}: \mathrm{C}, 61.47 ; \mathrm{H}, 7.74 ; \mathrm{S}, 6.48$. Found: C, 61.77; H, 7.53; S, 6.65 .

\subsubsection{Synthesis of 2,3,4,5-tetraethynylthiophene (M1)}

Under Ar atmosphere, 2,3,4,5-tetrakis[(trimethylsilyl)ethynyl]-thiophene (50 mg, $0.11 \mathrm{mmol}$ ) and potassium fluoride $(95.7 \mathrm{mg}, 1.65 \mathrm{mmol})$ were in the mixture of tetrahydrofuran $(10 \mathrm{~mL})$, methanol $(10 \mathrm{~mL})$. The reaction was stirred at room temperature for $2 \mathrm{~h}$. After $200 \mathrm{~mL}$ of water was added, the reaction mixture was extracted with ether and dried over $\mathrm{Na}_{2} \mathrm{SO}_{4}$. Since 2,3,4,5-tetraethynylthiophene is modestly stable in solvent at room temperature, the solvent was evaporated, and then pyridine $(50 \mathrm{~mL})$ was added under nitrogen atmosphere at room temperature. The solution was used for the next step. 
${ }^{1} \mathrm{H}$ NMR $(400 \mathrm{MHz}, \mathrm{CDCl} 3): \delta(\mathrm{ppm}) 3.58(\mathrm{~s}, 4 \mathrm{H}) .{ }^{13} \mathrm{C} \mathrm{NMR}\left(101 \mathrm{MHz}, \mathrm{CDCl}_{3}\right): \delta(\mathrm{ppm})$ $120.98,119.93,86.72,74.68$.

\subsubsection{Preparation of S-GDY Film}

Copper foil (area: $2 \times 2 \mathrm{~cm}^{2}$, thickness: $11 \pm 2 \mu \mathrm{m}$ ) was washed with $4 \mathrm{M}$ hydrochloric acid $(\mathrm{HCl})$, water, ethanol, and acetone, respectively, and dried under $\mathrm{Ar}$ atmosphere. Several (10) pieces of copper foil (area: $2 \times 2 \mathrm{~cm}^{2}$ ) and pyridine $(50 \mathrm{~mL}$ ) were added to a three-neck flask $(250 \mathrm{~mL})$. The mixture was heated at $60^{\circ} \mathrm{C}$ under $\mathrm{Ar}$ for $1 \mathrm{~h}$. The above solution with 2,3,4,5-tetraethynylthiophene and pyridine was transferred to an Ar-protected constant addition funnel and added dropwise into the mixture. After the addition of 2,3,4,5-tetraethynylthiophene, the reaction mixture was maintained at $60^{\circ} \mathrm{C}$ for 3 days. Upon completion of the reaction, the precipitation was filtered and washed with distilled water, ethanol, acetone, $\mathrm{CHCl}_{3}$, and methanol. After calcined at $400{ }^{\circ} \mathrm{C}$ for $2 \mathrm{~h}$, a black film was obtained on the copper foil and the thickness of S-GDY film was around $1.46 \mu \mathrm{m}$.

\subsection{Structure Characterizations}

Fourier transform infrared (FT-IR) spectra were recorded on a Nicolet 560 Fourier transform IR spectrometer (Thermo Scientific, Waltham, MA, USA). The XRD patterns were recorded using a Philips X'Pert PRO MPD (PANalytical B.V., Malvern, Holland). The Raman spectra were recorded on a LabRAM HR Raman Microscope (HORIBA Scientific, Paris, France) with an excitation length of $633 \mathrm{~nm}$ and a laser power of $0.5 \mathrm{~mW}$. Morphology details were examined using scanning electron microscopy (SEM, JEOL JSM-5900LV, JEOL Ltd., Tokyo, Japan), transmission electron microscopy (TEM, FEI Tecnai G2 F20 STWIN, FEI Company, Hillsboro, OR, USA). The STEM and elemental mapping images were obtained from FEI Titan G2 60-300 (AC-TEM, FEI Company, Hillsboro, OR, USA). X-ray photoelectron spectroscopy (XPS) measurement was carried out on a Kratos ASAM 800 analyzer (Kratos Analytical Ltd., Manchester, UK), performing at $12 \mathrm{kV}$ and $15 \mathrm{~mA}$ with a monochromatic $\mathrm{Al} \mathrm{K} \alpha$ source $(\mathrm{h} v=1486.6 \mathrm{eV})$. The nitrogen and adsorption-desorption measurements were performed on a BELSORB Max (MicrotracBEL Corp., Tokyo, Japan) sorption analyzer. The surface areas were calculated using the BET model in the pressure range $P / P_{0}$ from 0.05 to 0.3 . The total pore volume was determined at a relative pressure of 0.99 . The pore size distribution was analyzed from the gas adsorption data using an NLDFT method with a slit pore model.

\subsection{Electrochemical Measurements}

We used a typical Li-ion battery to estimate the electrochemical performances of S-GDY. Electrochemical experiments were performed using CR2032-type coin cells. The SGDY films grown on the copper foil were cut into a round shape (diameter $=12 \mathrm{~mm}$ ) and directly used as working electrodes without the addition of any binders. The current densities and capacities were calculated based on the active material of S-GDY with a low mass loading of about $0.24 \mathrm{mg} / \mathrm{cm}^{2}$. A pure $\mathrm{Li}$ foil was used as the counter electrode. The counter electrode was separated from the working electrode by a Celgard 2500 polymeric separator. The electrolyte consists of a solution of $1 \mathrm{M} \mathrm{LiPF}_{6}$ in ethylene carbonate (EC) and dimethyl carbonate (DMC) $(1: 1, v / v)$. We assembled the cells in an argon-filled glove box. The assembled half cells were cycled between 0.005 and $3 \mathrm{~V}$ using a LAND battery testing system (Wuhan, China). Cyclic voltammetry (CV) was carried out using a CHI760E electrochemical workstation (Shanghai, China) between $5 \mathrm{mV}$ and $3 \mathrm{~V} \mathrm{vs.} \mathrm{Li} / \mathrm{Li}^{+}$ at a scan rate of $1 \mathrm{mV} / \mathrm{s}$. Electrochemical impedance spectroscopy (EIS) was performed on a CHI760E electrochemical workstation by applying an AC voltage of $5 \mathrm{mV}$ amplitude at room temperature.

\section{Results and Discussion}

Herein, S-GDY with extended $\pi$-conjugated carbon skeletons comprised of butadiyne linkages and thiophene rings was prepared by a bottom-up synthetic strategy. The monomer 
2,3,4,5-tetraethynylthiophene (M1) was synthesized by a two-step synthesis. The synthetic route and related NMR spectra are described in the Supplementary Materials (Figures S1-S5, ESIt). Then, S-GDY was synthesized through an in situ cross-coupling reaction of the monomer M1 on copper foil in pyridine as a uniform black film (Figure 1). In the process of forming S-GDY films, the polymer particles are obtained by the catalysis of $\mathrm{Cu}$ (II) ion arising from the surface of the $\mathrm{Cu}$ foil in alkaline solution and then deposited on the copper foil to form a film [32]. For the convenience of characterizations, the S-GDY film could be collected by the dissolution of the copper substrate in a saturated $\mathrm{FeCl}_{3}$ solution.

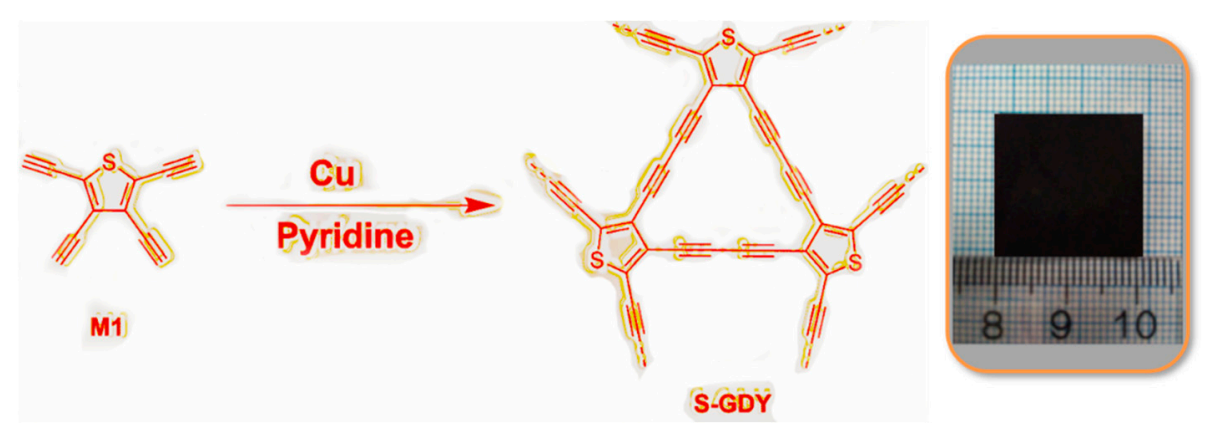

Figure 1. The preparation route and the photograph of S-GDY film on the copper foil.

The chemical structure of the sulfur-doped graphdiyne was confirmed by Fourier transform infrared spectroscopy (FT-IR) and Raman spectroscopy. The peaks at $1645 \mathrm{~cm}^{-1}$ and $1411 \mathrm{~cm}^{-1}$ in Figure $S 6$ can be assigned to the skeletal vibrations of the thiophene ring [30]. Meanwhile, a weak peak at around $2200 \mathrm{~cm}^{-1}$ corresponds to the typical $C \equiv C$ stretching vibration. Unlike Raman spectra of common carbon materials that exhibit obvious vibration peaks at the D band and G band, corresponding to the structural defects and highly ordered graphite carbon, respectively, the Raman spectrum of S-GDY presents a single $\mathrm{G}$ band vibration peak at $1533 \mathrm{~cm}^{-1}$ (Figure S7, ESIt), indicating a high regularity of the S-GDY film on the surface of copper foil. The weak peaks at $2142 \mathrm{~cm}^{-1}$ and $2285 \mathrm{~cm}^{-1}$ can be attributed to the stretching vibration of conjugated butadiyne linkage (-C $\equiv C-C \equiv C-)$ [33]. In addition, a broad 2D peak at $2800 \mathrm{~cm}^{-1}$ indicates that a multilayered structure exists [34]. Powder XRD patterns of S-GDY film show a broad peak at approximately $24^{\circ}$ (Figure S8, ESIt), indicating an overall amorphous structure, corresponding to a random accumulation of S-GDY at the macroscopic scale.

The quantity and species of elements in S-GDY were further investigated by X-ray photoelectron spectroscopy (XPS) analysis. XPS survey spectra of S-GDY show the main elements of O, C, and S (Figure S9, ESIt). The O 1s peak located at about $532.0 \mathrm{eV}$ could be mostly assigned to the adsorbed atmospheric oxygen-containing molecules and the oxidation of the acetylene group in the margin of the two-dimensional molecular plane $[19,35]$. The $S 2 p$ peak is located at about $163.0 \mathrm{eV}$ and the content ratio of the sulfur element is $7.48 \%$, which is close to the theoretical value ( $7.7 \%$ in atomic number ratio). C $1 \mathrm{~s}$ peak of S-GDY can be deconvoluted into four subpeaks, corresponding to the $\mathrm{C}=\mathrm{C}\left(\mathrm{sp}^{2}\right)$ at a binding energy of $284.2 \mathrm{eV}, \mathrm{C} \equiv \mathrm{C}(\mathrm{sp})$ at $284.7 \mathrm{eV}, \mathrm{C}-\mathrm{S}$ at $285.8 \mathrm{eV}$, and C-O at $287.6 \mathrm{eV}$ (Figure 2a) [36]. The high-resolution XPS spectra of S 2p (Figure 2b) reveal the presence of three kinds of $S$ configurations. The two evident peaks at 163.6 and $164.8 \mathrm{eV}$ belong to $S$ atoms connected with carbon (-C-S-C-), which are in agreement with the reported $2 \mathrm{p}_{3 / 2}$ and $2 p_{1 / 2}$ positions of thiophene $S$ owing to their spin-orbit coupling [36,37]. The weak and broad peak at $169.1 \mathrm{eV}$ is attributed to oxidized $\mathrm{S}\left(\mathrm{C}-\mathrm{SO}_{\mathrm{x}}-\mathrm{C}\right)$ [38]. These results confirm the successful doping of sulfur atoms into graphdiyne skeleton, which could provide more heteroatom defects and active sites to improve Li storage ability. 

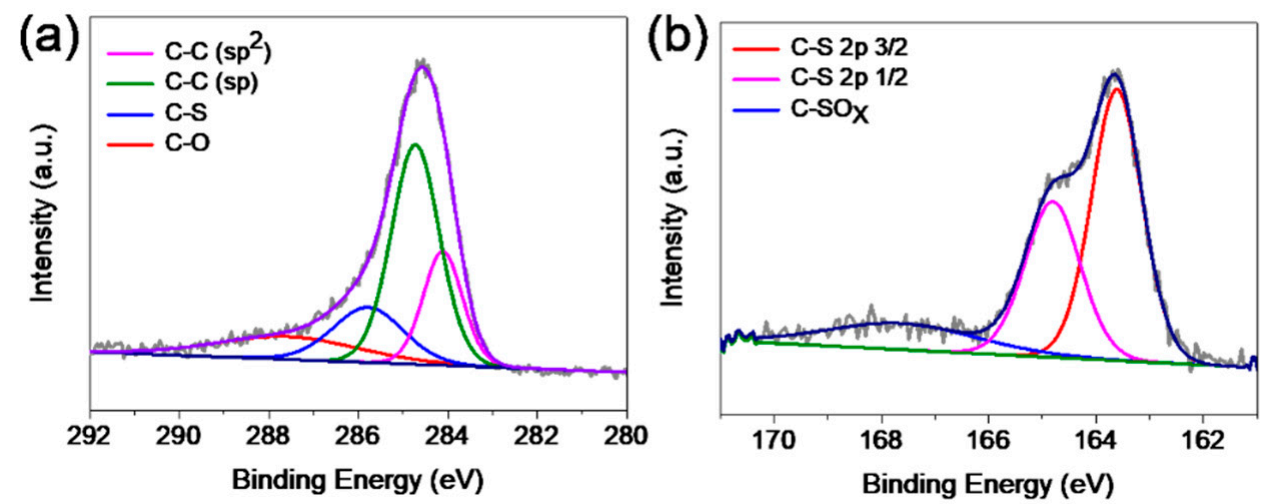

Figure 2. XPS spectra results: (a) C 1s binding energy profiles and (b) S 2p binding energy profiles.

The morphology of the S-GDY film was investigated by scanning electron microscopy (SEM) and transmission electron microscope (TEM). The cross-section SEM image shows that the film is continuous and its thickness is approximately $1.46 \mu \mathrm{m}$ (Figure 3a). Furthermore, the morphology of the side close to the copper substrate is more compact than that on the opposite side due to the template effect of the $\mathrm{Cu}$ foil. The top-view image shows that the S-GDY film has a rough surface with a large number of porous structures formed by the accumulation of small particles (Figure 3b), which would facilitate the movement and storage of electrolyte ions in LIBs application. TEM image (Figure 3c) shows the layer-by-layer stacking structure of S-GDY. High-resolution TEM (HRTEM) (Figure 3d) shows the interlayer spacing of S-GDY is $0.38 \mathrm{~nm}$, which is larger than that of graphene $(0.23 \mathrm{~nm})$ [39] and graphdiyne $(0.365 \mathrm{~nm})$ [15]. Selected-area electron diffraction (SAED) patterns (Figure 3e) reveal high crystallinity of S-GDY in certain areas. Elemental mapping images of S-GDY show the homogeneous distribution of carbon and sulfur atoms in its skeleton structure (Figure $3 \mathrm{f}-\mathrm{h}$ ). The porous properties and corresponding specific surface area of the polymer were measured by nitrogen adsorption and desorption experiment. As shown in Figure S10a, the specific surface area of the polymer calculated from the BET algorithm is $35 \mathrm{~m}^{2} \mathrm{~g}^{-1}$, while the pore size distribution (PSD) curves in Figure S10b indicate that the pore size is mainly distributed in the mesoporous region.
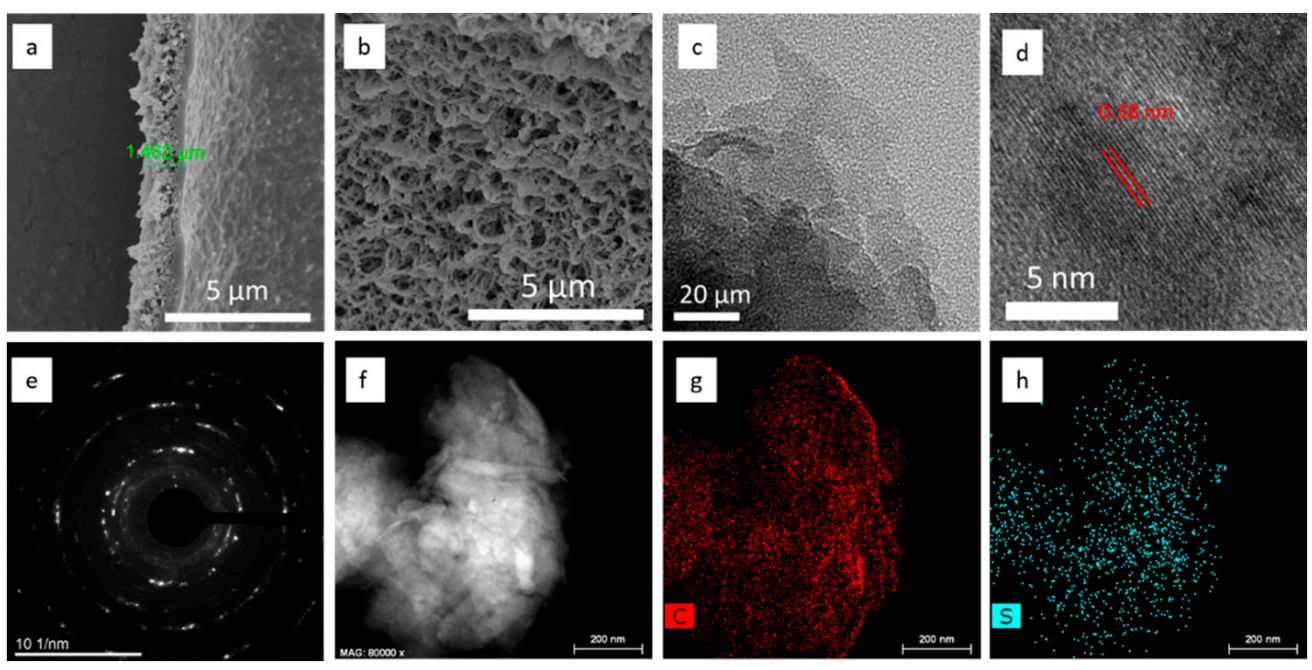

Figure 3. The morphology of S-GDY film: (a) the cross-section SEM image of the S-GDY film, (b) the top-view SEM image of the S-GDY film, (c) TEM image of the S-GDY, (d) HRTEM image of the S-GDY, (e) SAED pattern of the S-GDY, and (f) scanning transmission electron microscopy image and elemental mapping of (g) C-K and (h) S-K. 
The electrochemical performances of S-GDY were evaluated by assembling S-GDY / $\mathrm{LiPF}_{6}$ electrolyte/Li metal half cells and testing in the potential range of $0.005-3.0 \mathrm{~V} \mathrm{vs}$. $\mathrm{Li} / \mathrm{Li}^{+}$. The electrode is prepared by cutting S-GDY films grown on the copper foil into pieces without any addition of polymer binder and conductive agent. The first three cyclic voltammetry $(\mathrm{CV})$ curves shown in Figure 4a were measured at a scan rate of $1 \mathrm{mV} / \mathrm{s}$. It can be recognized that a cathodic peak is found at around $0.5 \mathrm{~V}$, which represents the formation of a new chemical structure [22]. Another two redox peaks at 1.4 and $2.6 \mathrm{~V}$ correspond to the reversible redox reaction of the thiophene unit [30], suggesting that S-GDY exhibits electrochemical activity and stability. The galvanostatic charge-discharge profiles of the initial three cycles of the half cells at the current density of $0.1 \mathrm{~A} \mathrm{~g}^{-1}$ $\left(0.024 \mathrm{~mA} \mathrm{~cm}^{-2}\right)$ are shown in Figure $4 \mathrm{~b}$. At the first cycle, a large specific capacity of $1678 \mathrm{~mA} \mathrm{~h} \mathrm{~g}^{-1}\left(0.04 \mathrm{~mA} \mathrm{~h} \mathrm{~cm}^{-2}\right)$ and high Coulombic efficiency (CE) of $68.8 \%$ are obtained from this electrode, indicating that doping $\mathrm{S}$ atoms could improve the Li adsorption ability and thus lead to a large capacity [40].

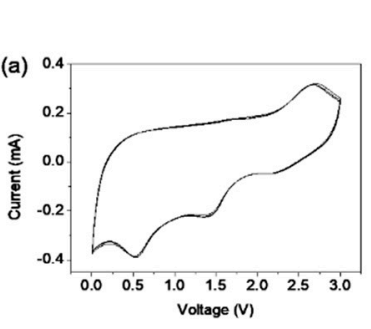

(d)
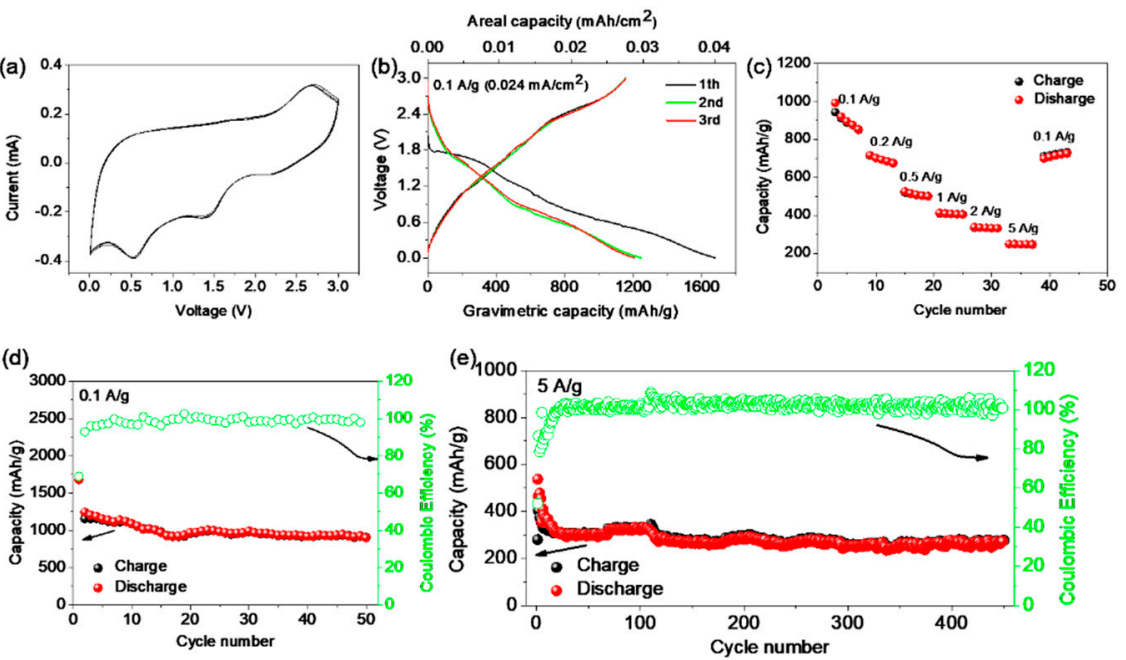

Figure 4. The electrochemical performances of S-GDY electrodes in Li metal half-cell format: (a) the first three cyclic voltammetry $(\mathrm{CV})$ curves at a scan rate of $1 \mathrm{mV} / \mathrm{s},(\mathbf{b})$ galvanostatic charge-discharge profiles at a current density of $0.1 \mathrm{~A} / \mathrm{g}\left(0.024 \mathrm{~mA} \mathrm{~cm}^{-2}\right)$, recorded between $5 \mathrm{mV}$ and $3 \mathrm{~V}$, (c) the rate performance, $(\mathbf{d})$ the cycle performance at the current density of $0.1 \mathrm{~A} \mathrm{~g}^{-1}$, and (e) the cycle performance at the current density of $5 \mathrm{~A} \mathrm{~g}^{-1}$.

Rate performances of the S-GDY electrode from 0.1 to $5 \mathrm{~A} \mathrm{~g}^{-1}$ are shown in Figure 4c. The reversible gravimetric capacity of the S-GDY retains to be $248 \mathrm{~mA} \mathrm{~h} \mathrm{~g}^{-1}$, while the current density is increased to $5 \mathrm{~A} \mathrm{~g}^{-1}$, demonstrating that S-GDY prepared by this "bottomup" method exhibits excellent rate capacities. In addition, long-term cycling performances of these electrodes are also measured. At a current density of $0.1 \mathrm{~A} \mathrm{~g}^{-1}$, the reversible capacity can reach $920 \mathrm{~mA} \mathrm{~h} \mathrm{~g}^{-1}$ after 50 cycles and the Coulombic efficiency on average is nearly $99 \%$ (Figure $4 \mathrm{~d}$ ), which is comparable to the state-of-the-art reported carbonbased materials (Table S1, ESIt). More intriguingly, even under higher current densities of $0.5 \mathrm{~A} \mathrm{~g}^{-1}, 1 \mathrm{~A} \mathrm{~g}^{-1}$, S-GDY-based electrodes also display decent capacities of $675 \mathrm{~mA} \mathrm{~h} \mathrm{~g}^{-1}$ and $423 \mathrm{~mA} \mathrm{~h} \mathrm{~g}^{-1}$, respectively, after long cycles (Figures S11 and S12, ESI†). The specific capacity of S-GDY remains to be $275 \mathrm{~mA} \mathrm{~h} \mathrm{~g}^{-1}$ after 500 cycles under a current density of $5 \mathrm{~A} \mathrm{~g}^{-1}$, as shown in Figure 4e.

Electrochemical impedance spectroscopy (EIS) was employed to investigate the interfacial charge transfer and $\mathrm{Li}^{+}$diffusion process. Nyquist plots and corresponding equivalent circuits of the S-GDY electrode before and after cycling at $0.5 \mathrm{~A} \mathrm{~g}^{-1}$ are shown in Figure S13. The semicircle in the Nyquist plot corresponds to the charge transfer process of electrodes before cycling, while the semicircle after 120 cycles is ascribed to combination resistance of solid electrolyte interphase (SEI) films and charge transfer process. The fitting 
kinetic parameters of the electrodes are listed in Table 1. It can be observed that the S-GDY electrode shows a much lower charge-transfer resistance $\left(R_{\mathrm{ct}}\right)$ after cycling, indicating enhanced charge transportation ability and a higher $\mathrm{Li}^{+}$diffusion rate during cycling [19]. In addition, the morphology of the S-GDY electrode after cycling was investigated and the results in Figure S14 reveal the formation of an SEI layer. All these results indicate that S-GDY is a promising anode material for LIBs probably due to the synergistic effect of sulfur doping and porous structure. The introduction of $S$ atoms could provide more heteroatom defects and electrochemically active sites, and the porous structure facilitates the adsorption-desorption and diffusion of $\mathrm{Li}$ ions.

Table 1. Kinetic parameters of the S-GDY electrode before and after 120 cycles at the current density of $0.5 \mathrm{~A} \mathrm{~g}^{-1}$.

\begin{tabular}{ccc}
\hline S-GDY & Before Cycles & After 120 Cycles \\
\hline$R_{\mathrm{e}}(\Omega)$ & 5.7 & 4.5 \\
$\mathrm{R}_{\mathrm{s}}(\Omega)$ & - & 4.4 \\
$\mathrm{R}_{\mathrm{ct}}(\Omega)$ & 236.9 & 5.9 \\
\hline
\end{tabular}

\section{Conclusions}

In conclusion, sulfur-doped graphdiyne (S-GDY), a distinctive two-dimensional heteroatom doped carbon material, was designed and prepared by a "bottom-up" method on the surface of copper foil using a sulfur-containing multi-acetylene monomer. The obtained S-GDY possesses abundant sulfur atoms decorated homogeneously in the carbon skeleton and exhibits enhanced electrochemical performance due to the synergistic effect of sulfur doping and porous structure. The S-GDY film proves to be a promising anode material with a highly reversible specific capacity up to $920 \mathrm{~mA} \mathrm{~h} \mathrm{~g}^{-1}$ at a current density of $0.1 \mathrm{~A} \mathrm{~g}^{-1}$ and excellent rate performances. The specific capacity of S-GDY can still retain $275 \mathrm{~mA} \mathrm{~h} \mathrm{~g}^{-1}$ after 500 cycles under a high current density of $5 \mathrm{~A} \mathrm{~g}^{-1}$. Overall, this "bottom-up" method could potentially provide a rational design principle for the construction of heteroatom-doped carbon materials to be used as high-performance anode materials for lithium-ion batteries.

Supplementary Materials: The following are available online at https://www.mdpi.com/article/10 $.3390 /$ nano11051161/s1, Figure S1: Synthesis of 2,3,4,5-tetrakis[(trimethylsilyl)ethynyl]-thiophene (2) and 2,3,4,5-tetraethynyl thiophene (M1); Figure S2: ${ }^{1} \mathrm{H}$ NMR spectrum of 2,3,4,5-tetrakis[(trimethylsilyl) ethynyl]-thiophene (2); Figure S3: ${ }^{13} \mathrm{C}$ NMR spectrum of 2,3,4,5-tetrakis[(trimethylsilyl)ethynyl]thiophene (2); Figure S4: ${ }^{1} \mathrm{H}$ NMR spectrum of 2,3,4,5-tetraethynyl thiophene (M1); Figure S5: ${ }^{13}$ C NMR spectrum of 2,3,4,5-tetraethynyl thiophene (M1); Figure S6: FT-IR spectrum of S-GDY; Figure S7: Raman spectrum of S-GDY; Figure S8: Power XRD pattern of S-GDY; Figure S9: XPS survey spectrum of S-GDY; Figure S10: (a) Nitrogen adsorption-desorption isotherms of S-GDY, (b) pore size distribution profile from NLDFT calculation. Figure S11: Long-term capacity retention at a current density of $0.5 \mathrm{~A} \mathrm{~g}^{-1}$; Figure S12: Long-term capacity retention at a current density of $1 \mathrm{~A} \mathrm{~g}^{-1}$; Figure S13: (a) Nyquist plots of the S-GDY electrode before and after 120 cycles at $0.5 \mathrm{~A} \mathrm{~g}^{-1}$. The inset shows a S-GDY electrode after cycling alone in the enlarged part of the high-frequency region. (b) Equivalent circuits of the S-GDY electrode. In the equivalent circuit, $R_{e}$ represents the electrolyte resistance; $R_{S}$ is the equivalent resistance of the SEI layer formed on the electrode; $R_{c t}$ is the charge-transfer resistance; $Z_{\mathrm{W}}$ is the Warburg impedance; $\mathrm{CPE}$ represents the corresponding double-layer capacitance. Figure S14: The SEM images of the S-GDY electrode after 120 cycles at $0.5 \mathrm{~A} \mathrm{~g}^{-1}$; Table S1: Comparison of the performance of previously reported carbon-based materials with S-GDY.

Author Contributions: Conceptualization and methodology, S.R.; investigation, Y.Y. and F.K.; writing-original draft preparation, Y.Y., F.K. and Q.L.; writing-review and editing, F.K. and S.R.; supervision, S.R.; funding acquisition, S.R. All authors have read and agreed to the published version of the manuscript. 
Funding: This work was financially supported by the National Natural Science Foundation of China (51973128, 21574087) and the Science and Technology Department of Sichuan Province (2019YJ0128, 2019YFG0277).

Conflicts of Interest: The authors declare no conflict of interest.

\section{References}

1. Li, B.; Zheng, J.; Zhang, H.; Jin, L.; Yang, D.; Lv, H.; Shen, C.; Shellikeri, A.; Zheng, Y.; Gong, R.; et al. Electrode Materials, Electrolytes, and Challenges in Nonaqueous Lithium-Ion Capacitors. Adv. Mater. 2018, 30, 1705670. [CrossRef]

2. Kostopoulou, A.; Vernardou, D.; Savva, K.; Stratakis, E. All-Inorganic Lead Halide Perovskite Nanohexagons for High Performance Air-Stable Lithium Batteries. Nanoscale 2019, 11, 882-889. [CrossRef]

3. Shang, H.; Zuo, Z.; Li, L.; Wang, F.; Liu, H.; Li, Y.; Li, Y. Ultrathin Graphdiyne Nanosheets Grown In Situ on Copper Nanowires and Their Performance as Lithium-Ion Battery Anodes. Angew. Chem. Int. Ed. Engl. 2018, 57, 774-778. [CrossRef]

4. Yang, C.; Qiao, C.; Chen, Y.; Zhao, X.; Wu, L.; Li, Y.; Jia, Y.; Wang, S.; Cui, X. Nitrogen Doped gamma-Graphyne: A Novel Anode for High-Capacity Rechargeable Alkali-Ion Batteries. Small 2020, 16, 1907365. [CrossRef]

5. Yue, Z.; Dunya, H.; Ashuri, M.; Kucuk, K.; Aryal, S.; Antonov, S.; Alabbad, B.; Segre, C.U.; Mandal, B.K. Synthesis of a Very High Specific Surface Area Active Carbon and Its Electrical Double-Layer Capacitor Properties in Organic Electrolytes. ChemEngineering 2020, 4, 43. [CrossRef]

6. Ji, L.; Lin, Z.; Alcoutlabi, M.; Zhang, X. Recent Developments in Nanostructured Anode Materials for Rechargeable Lithium-Ion Batteries. Energy Environ. Sci. 2011, 4, 2682-2699. [CrossRef]

7. Zhang, C.; Kong, R.; Wang, X.; Xu, Y.; Wang, F.; Ren, W.; Wang, Y.; Su, F.; Jiang, J.-X. Porous Carbons Derived from Hypercrosslinked Porous Polymers for Gas Adsorption and Energy Storage. Carbon 2017, 114, 608-618. [CrossRef]

8. Ai, W.; Jiang, J.; Zhu, J.; Fan, Z.; Wang, Y.; Zhang, H.; Huang, W.; Yu, T. Supramolecular Polymerization Promoted in Situ Fabrication of Nitrogen-Doped Porous Graphene Sheets as Anode Materials for Li-Ion Batteries. Adv. Energy Mater. 2015, 5, 1500559. [CrossRef]

9. Endo, M.; Kim, C.; Nishimura, K.; Fujino, T.; Miyashita, K. Recent Development of Carbon Materials for Li Ion Batteries. Carbon 2000, 38, 183-197. [CrossRef]

10. Zhang, S.; Liu, H.; Huang, C.; Cui, G.; Li, Y. Bulk Graphdiyne Powder Applied for Highly Efficient Lithium Storage. Chem. Commun. 2015, 51, 1834-1837. [CrossRef]

11. Li, G.; Li, Y.; Liu, H.; Guo, Y.; Li, Y.; Zhu, D. Architecture of Graphdiyne Nanoscale Films. Chem. Commun. 2010, 46, 3256-3258. [CrossRef] [PubMed]

12. Lv, Q.; Si, W.; He, J.; Sun, L.; Zhang, C.; Wang, N.; Yang, Z.; Li, X.; Wang, X.; Deng, W.; et al. Selectively Nitrogen-Doped Carbon Materials as Superior Metal-free Catalysts for Oxygen Reduction. Nat. Commun. 2018, 9, 3376. [CrossRef] [PubMed]

13. Liu, R.; Gao, X.; Zhou, J.; Xu, H.; Li, Z.; Zhang, S.; Xie, Z.; Zhang, J.; Liu, Z. Chemical Vapor Deposition Growth of Linked Carbon Monolayers with Acetylenic Scaffoldings on Silver Foil. Adv. Mater. 2017, 29, 1604665. [CrossRef] [PubMed]

14. Liu, R.; Zhou, J.; Gao, X.; Li, J.; Xie, Z.; Li, Z.; Zhang, S.; Tong, L.; Zhang, J.; Liu, Z. Graphdiyne Filter for Decontaminating Lead-Ion-Polluted Water. Adv. Electron. Mater. 2017, 3, 1700122. [CrossRef]

15. Huang, C.; Zhang, S.; Liu, H.; Li, Y.; Cui, G.; Li, Y. Graphdiyne for High Capacity and Long-Life Lithium Storage. Nano Energy 2015, 11, 481-489. [CrossRef]

16. Yang, Z.; Wang, N.; He, J.; Wang, K.; Li, X.; Shen, X.; Wang, X.; Lv, Q.; Zhang, M.; Jiu, T. Triazine-Graphdiyne: A New Nitrogen-Carbonous Material and Its Application as an Advanced Rechargeable Battery Anode. Carbon 2018, 137, 442-450. [CrossRef]

17. Yang, Z.; Shen, X.; Wang, N.; He, J.; Li, X.; Wang, X.; Hou, Z.; Wang, K.; Gao, J.; Jiu, T.; et al. Graphdiyne Containing Atomically Precise N Atoms for Efficient Anchoring of Lithium Ion. ACS Appl. Mater. Interfaces 2019, 11, 2608-2617. [CrossRef] [PubMed]

18. Pan, Q.; Chen, S.; Wu, C.; Zhang, Z.; Li, Z.; Zhao, Y. Sulfur-rich Graphdiyne-Containing Electrochemical Active Tetrathiafulvalene for Highly Efficient Lithium Storage Application. ACS Appl. Mater. Interfaces 2019, 11, 46070-46076. [CrossRef]

19. Wang, N.; He, J.; Tu, Z.; Yang, Z.; Zhao, F.; Li, X.; Huang, C.; Wang, K.; Jiu, T.; Yi, Y.; et al. Synthesis of Chlorine-Substituted Graphdiyne and Applications for Lithium-Ion Storage. Angew. Chem. Int. Ed. 2017, 56, 10740-10745. [CrossRef] [PubMed]

20. He, J.; Wang, N.; Cui, Z.; Du, H.; Fu, L.; Huang, C.; Yang, Z.; Shen, X.; He, J.; Du, H.; et al. Hydrogen Substituted Graphdiyne as Carbon-Rich Flexible Electrode for Lithium and Sodium Ion Batteries. Nat. Commun. 2017, 8, 1172. [CrossRef]

21. Wang, N.; Li, X.; Tu, Z.; Zhao, F.; He, J.; Guan, Z.; Huang, C.; Yi, Y.; Li, Y. Synthesis and Electronic Structure of Boron-Graphdiyne with an sp-Hybridized Carbon Skeleton and Its Application in Sodium Storage. Angew. Chem. Int. Ed. 2018, 57, 3968-3973. [CrossRef] [PubMed]

22. He, J.; Wang, N.; Yang, Z.; Shen, X.; Wang, K.; Huang, C.; Yi, Y.; Tu, Z.; Li, Y. Fluoride Graphdiyne as a Free-Standing Electrode Displaying Ultra-Stable and Extraordinary High Li Storage Performance. Energy Environ. Sci. 2018, 11, 2893-2903. [CrossRef]

23. Yue, Y.; Xu, Y.; Kong, F.; Li, Q.; Ren, S. Bulk-Synthesis and Supercapacitive Energy Storage Application of Nanoporous TriazineBased Graphdiyne. Carbon 2020, 167, 202-208. [CrossRef]

24. Lv, Q.; Wang, N.; Si, W. Pyridinic Nitrogen Exclusively Doped Carbon Materials as Efficient Oxygen Reduction Electrocatalysts for Zn-Air Batteries. Appl. Catal. B 2019, 261, 1-9. [CrossRef] 
25. Kotal, M.; Kim, J.; Kim, K.J.; Oh, I.K. Sulfur and Nitrogen Co-Doped Graphene Electrodes for High-Performance Ionic Artificial Muscles. Adv. Mater. 2016, 28, 1610-1615. [CrossRef] [PubMed]

26. Yang, J.; Zhou, X.; Wu, D.; Zhao, X.; Zhou, Z. S-Doped N-Rich Carbon Nanosheets with Expanded Interlayer Distance as Anode Materials for Sodium-Ion Batteries. Adv. Mater. 2017, 29, 1604108. [CrossRef] [PubMed]

27. Yang, Z.; Cui, W.; Wang, K.; Song, Y.; Zhao, F.; Wang, N.; Long, Y.; Wang, H.; Huang, C. Chemical Modification of the sp-Hybridized Carbon Atoms of Graphdiyne by Using Organic Sulfur. Chem. Eur. J. 2019, 25, 5643-5647. [CrossRef]

28. Du, H.; Zhang, Z.; He, J.; Cui, Z.; Chai, J.; Ma, J.; Yang, Z.; Huang, C.; Cui, G. A Delicately Designed Sulfide Graphdiyne Compatible Cathode for High-Performance Lithium/Magnesium-Sulfur Batteries. Small 2017, 13, 1702277. [CrossRef] [PubMed]

29. Snook, G.A.; Kao, P.; Best, A.S. Conducting-Polymer-Based Supercapacitor Devices and Electrodes. J. Power Source 2011, 196, 1-12. [CrossRef]

30. Zhang, C.; He, Y.; Mu, P.; Wang, X.; He, Q.; Chen, Y.; Zeng, J.; Wang, F.; Xu, Y.; Jiang, J.-X. Toward High Performance ThiopheneContaining Conjugated Microporous Polymer Anodes for Lithium-Ion Batteries through Structure Design. Adv. Funct. Mater. 2018, 28, 1705432. [CrossRef]

31. Wang, K.; Li, X.; Xie, Y.; He, J.; Yang, Z.; Shen, X.; Wang, N.; Huang, C. Artificial Thiophdiyne Ultrathin Layer as an Enhanced Solid Electrolyte Interphase for the Aluminum Foil of Dual-Ion Batteries. ACS Appl. Mater. Interfaces 2019, 11, 23990-23999. [CrossRef] [PubMed]

32. Zhou, J.; Gao, X.; Liu, R.; Xie, Z.; Yang, J.; Zhang, S.; Zhang, G.; Liu, H.; Li, Y.; Zhang, J. Synthesis of Graphdiyne Nanowalls Using Acetylenic Coupling Reaction. J. Am. Chem. Soc. 2015, 137, 7596-7599. [CrossRef] [PubMed]

33. Matsuoka, R.; Sakamoto, R.; Hoshiko, K.; Sasaki, S.; Masunaga, H.; Nagashio, K.; Nishihara, H. Crystalline Graphdiyne Nanosheets Produced at a Gas/Liquid or Liquid/Liquid Interface. J. Am. Chem. Soc. 2017, 139, 3145-3152. [CrossRef] [PubMed]

34. Wen, Z.; Wang, X.; Mao, S.; Bo, Z.; Kim, H.; Cui, S.; Lu, G.; Feng, X.; Chen, J. Crumpled Nitrogen-Doped Graphene Nanosheets with Ultrahigh Pore Volume for High-Performance Supercapacitor. Adv. Mater. 2012, 24, 5610-5616. [CrossRef] [PubMed]

35. Xu, Y.; Wu, S.; Ren, S.; Ji, J.; Yue, Y.; Shen, J. Nitrogen-Doped Porous Carbon Materials Generated via Conjugated Microporous Polymer Precursors for $\mathrm{CO}_{2}$ Capture and Energy Storage. RSC Adv. 2017, 7, 32496-32501. [CrossRef]

36. Li, W.; Yang, D.; Chen, H.; Gao, Y.; Li, H. Sulfur-Doped Carbon Nanotubes as Catalysts for the Oxygen Reduction Reaction in Alkaline Medium. Electrochim. Acta 2015, 165, 191-197. [CrossRef]

37. Louisiaa, S.; Contrerasa, R.C.; Heitzmannb, M.; Axeta, M.R.; Jacquesb, P.-A.; Serpa, P. Sequential Catalytic Growth of Sulfur-Doped Carbon Nanotubes and Their Use as Catalyst Support. Catal. Commun. 2018, 109, 65-70. [CrossRef]

38. Jiang, T.; Wang, Y.; Wang, K.; Liang, Y.; Wu, D.; Tsiakarasb, P.; Song, S. A Novel Sulfur-Nitrogen Dual Doped Ordered Mesoporous Carbon Electrocatalyst for Efficient Oxygen Reduction Reaction. Appl. Catal. B 2016, 189, 1-11. [CrossRef]

39. Reina, A.; Jia, X.; Ho, J.; Nezich, D.; Son, H.; Bulovic, V.; Dresselhaus, M.S.; Kong, J. Large Area, Few-Layer Graphene Films on Arbitrary Substrates by Chemical Vapor Deposition. Nano Lett. 2008, 9, 30-35. [CrossRef]

40. Wang, T.; Zhai, P.; Legut, D.; Wang, L.; Liu, X.; Li, B.; Dong, C.; Fan, Y.; Gong, Y.; Zhang, Q. S-Doped Graphene-Regional Nucleation Mechanism for Dendrite-Free Lithium Metal Anodes. Adv. Energy Mater. 2019, 9, 1804000. [CrossRef] 